\title{
8
}
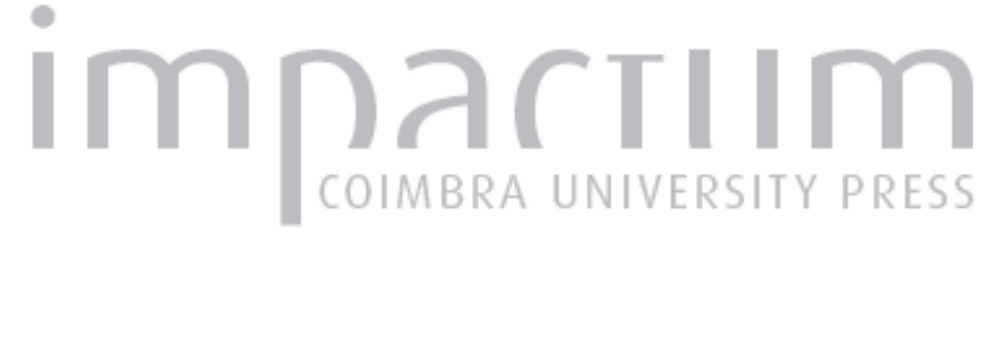

\section{Perfil dos imóveis e dos ocupantes da Floresta Estadual de Rendimento Sustentado do Rio Mequéns, no Estado de Rondônia}

\author{
Autor(es): $\quad$ Theodoro, J.; Silveira, E. G.; Della-Justina, E. E.; Ferreira, M. M.; Cunha, \\ L.; Moret, S. A.; Silva Filho, E. P.; Barata, C. S.
}

Publicado por: Imprensa da Universidade de Coimbra

URL

persistente:

URI:http://hdl.handle.net/10316.2/40776

DOI:

DOI:https://doi.org/10.14195/0871-1623_35_7

Accessed : $\quad$ 26-Apr-2023 11:51:18

A navegação consulta e descarregamento dos títulos inseridos nas Bibliotecas Digitais UC Digitalis, UC Pombalina e UC Impactum, pressupõem a aceitação plena e sem reservas dos Termos e Condições de Uso destas Bibliotecas Digitais, disponíveis em https://digitalis.uc.pt/pt-pt/termos.

Conforme exposto nos referidos Termos e Condições de Uso, o descarregamento de títulos de acesso restrito requer uma licença válida de autorização devendo o utilizador aceder ao(s) documento(s) a partir de um endereço de IP da instituição detentora da supramencionada licença.

Ao utilizador é apenas permitido o descarregamento para uso pessoal, pelo que o emprego do(s) título(s) descarregado(s) para outro fim, designadamente comercial, carece de autorização do respetivo autor ou editor da obra.

Na medida em que todas as obras da UC Digitalis se encontram protegidas pelo Código do Direito de Autor e Direitos Conexos e demais legislação aplicável, toda a cópia, parcial ou total, deste documento, nos casos em que é legalmente admitida, deverá conter ou fazer-se acompanhar por este aviso.

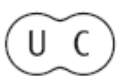




\title{
Perfil dos imóveis e dos ocupantes da Floresta Estadual de Rendimento Sustentado do Rio Mequéns, no Estado de Rondônia Profile of the immovable properties and of the occupants of the State Forest of Sustained Yield of Mequéns River, in the State of Rondônia
}

\author{
J. Theodoro \\ Doutoranda em Geografia/Universidade de Coimbra e pesquisadora do Grupo de pesquisa Energia Renovável Sustentável/Fundação Universidade Federal de \\ Rondônia \\ jucitheodoro@hotmail.com
}

\section{E. G. Silveira}

Professor do Departamento de Geografia e Programa de Pós Graduação em Desenvolvimento Regional e Meio Ambiente/Fundação Universidade Federal de Rondônia

ene_gloria@yahoo.com.br

\section{E. E. Della-Justina}

Professora do Departamento de Geografia e do Programa de Pós Graduação em Geografia e pesquisadora do Laboratório de Cartografia - Labcart/Fundação Universidade Federal de Rondônia

eloizadella@gmail.com

\section{M. Ferreira}

Pesquisadora do Laboratório de Cartografia e professora do Programa de Pós Graduação em Letra/Fundação Universidade Federal de Rondônia madhafer2004@yahoo.com.br

\section{Cunha}

Departamento de Geografia e Turismo da Faculdade de Letras da Universidade de Coimbra e CEGOT - Centro de Estudos de Geografia e Ordenamento do Território

luciogeo@fl.uc.pt

\section{S. A. Moret}

Professor do Programa de Pós Graduação em Desenvolvimento Regional e Meio Ambiente e pesquisador do Grupo de pesquisa Energia Renovável Sustentável/ Fundação Universidade Federal de Rondônia

artutmoret@ig.com.br

\section{E. P. Silva Filho}

Professor do Departamento de Geografia e do Programa de Pós Graduação em Geografia. Fundação Universidade Federal de Rondônia eliomarfilho@uol.com.br

\section{S. Barata}

Mestrando do Programa de Pós Graduação em Geografia/Fundação Universidade Federal de Rondônia charllesbarata@hotmail.com

\section{Resumo:}

A ocupação da Amazônia Brasileira passa a ser intensiva na década de 1970, a partir da implantação dos projetos de colonização dirigida, convergindo para um intenso desmatamento e ocupações irregulares, conhecida como a "Década da Destruição". O Estado de Rondônia recebeu diversos destes projetos, sofrendo grande ocupação, estimulada por programas oficiais de colonização. A busca por áreas de produção agrícola e agropecuária e de exploração madeireira propiciou a rápida ocupação de todos os espaços disponíveis para tais fins, em Rondônia, restando apenas as áreas destinadas a preservação. Entretanto estas áreas não ficaram isentas de ocupação ilegal. Muitos fatores favoreceram e contribuíram para este tipo de ação criminosa. A ocupação efetiva de áreas protegidas serviu de argumento para o Governo do Estado de Rondônia propor a revogação das várias Unidades de Conservação (UC), entregando as terras definitivamente aos prevaricadores ambientais. Este trabalho analisa a situação da Floresta Estadual de Rendimento Sustentável do Rio Mequéns (FERS), UC criada no ano de 1990 e revogada por solicitação do Governo do Estado de Rondônia, no ano de 2010. Neste trabalho são apresentados os resultados dos estudos realizados sobre a FERS do Rio Mequéns, especialmente nos primeiros anos de existência. A partir da análise de tais dados, elaborou-se um perfil fundiário da referida Unidade de 
Conservação, com indicadores dos imóveis, dimensão, uso, tempo de ocupação entre outros elementos, bem como um perfil dos proprietários destes imóveis e da população que habita o espaço da UC em tela. Elencam-se, também, os principais fatores que contribuíram para a ocupação da FERS do Rio Mequéns.

Palavras-Chave: Unidades de Conservação. Ocupação ilegal. FERS Rio Mequéns. Rondônia.

\section{Abstract:}

The Brazilian Amazon forest became intensively occupied in the decade of 1970, also known as "Decade of Destruction", with the implementation of colonization projects that led to an intense deforestation and an irregular occupation. Several of those projects were implemented in Rondônia state, where the occupation process was stimulated by official colonization programs. The search for areas of agricultural production, livestock and logging, led to the occupation of all the available spaces in Rondônia, leaving only the areas for preservation. However, those areas were not spared from illegal occupation. Several factors contributed to this kind of criminal attitude. The effective occupation of protected areas was used as an argument by the government of Rondônia state to propose the revocation of several Conservation Units (UC), delivering those areas definitely to the environmental transgressors. This study evaluates the Floresta Estadual de Rendimento Sustentável do Rio Mequéns (FERS), which is a conservation unit created in 1990 and revoked in 2010 due to Rondônia government requirement. This paper presents the results of the studies performed on the FERS Mequéns River, especially in the first years of its existence. From the analysis of data, a landed profile was made for the referred conservation unit, considering as indicators immovable properties, dimensions, utilization, time of occupation and other elements, such as the profile of the owners of the immovable properties and the population inhabiting the space of the UC. The main factors that contributed to the occupation of the FERS Mequéns River were also documented.

Keywords: Conservation Units. Illegal occupation. FERS Mequéns River. Rondônia.

\section{A ocupação e o desflorestamento do Estado de Rondônia}

O Território Federal do Guaporé foi formado a partir de terras desmembradas dos estados do Amazonas e do Mato Grosso, no ano de 1949, sofrendo alterações na sua configuração territorial no ano de 1956 quando, por decisão do Congresso Federal, passou a ser denominado Território Federal de Rondônia em homenagem ao Marechal Cândido Mariano da Silva Rondon, pioneiro na exploração da região. Foi elevado à categoria de Estado no ano de 1981, passando desde então a constituir as Unidades Federativas do Brasil como Estado de Rondônia. Localizadas na parte ocidental da Amazônia brasileira, as terras pertencentes ao atual Estado de Rondônia encontravam-se até ao início da segunda metade do século XX praticamente sem ocupação significativa, com as populações indígenas concentradas principalmente no médio e alto rio Madeira e os migrantes remanescentes dos dois ciclos da borracha, distribuídos nos vales dos rios Madeira e Mamoré. Os principais centros urbanos da região eram Porto Velho (capital) e Guajará Mirim, na divisa com a Bolívia, além de pequenas aglomerações ao longo do vale do rio Guaporé. A abertura da rodovia BR364, instalada na década de 1960 , foi o marco da apropriação definitiva desta região, pois possibilitou os transportes, facilitando o processo migratório e consolidando a ocupação em Rondônia. Os projetos de colonização, implantados pelo Instituto Nacional de Colonização e Reforma Agrária (INCRA), levaram à rápida expansão das atividades agropecuárias e a elevados índices de desmatamento (Azevedo, 2002; Dantas, 2010; Fearnside, 1991; Fearnside, 2005; Oliveira, 2001; Oliveira, 2003; Santos, 2007).

Um dos programas governamentais que mais contribuíram para o desflorestamento do Estado de Rondônia foi o Programa Integrado de Desenvolvimento do Noroeste do Brasil (POLONOROESTE), que tinha por objetivo a promoção do desenvolvimento socioeconômico do norte do estado do Mato Grosso e do estado de Rondônia. Entretanto, o modelo fundiário escolhido não levou em conta a realidade e as peculiaridades do contexto amazônico, como a fertilidade das terras produtivas e o clima quente e úmido durante todo o ano, implementando junto dos produtores práticas agrícolas comuns a outras regiões do país, como a derrubada e a queimada para o preparo do plantio, práticas estas que a médio e longo prazo provaram ser danosas e insustentáveis no contexto amazônico. A exigência de benfeitorias como prova de posse da propriedade, necessárias para a obtenção do Título Definitivo da terra, funcionou como um incentivo ao desmatamento. Tais ações eram comuns e mesmo incentivadas pelos gestores do POLONOROESTE e por parte das autoridades regionais. As questões políticas sempre estiveram no cerne da ocupação do espaço rondoniense. Uma situação esdrúxula e muito comum era a troca de lotes/parcelas de terras por votos, criando-se "currais eleitorais"1 no Estado, cuja influência ainda perdura em diversas localidades, como reduto

\footnotetext{
Expressão utilizada por historiadores brasileiros que indica uma região fortemente controladas por determinados políticos.
} 
eleitoral do "político fulano de tal" (Fearnside, 2006; INPE, 1992; Laurance et al, 2004; Leonel, 1992; Matricardi, 1996; Miranda, 1992; Nunes, 1997; Perdigão e Basségio, 1992; Santos, 1998; Tocantins, 1982).

A pressão e as duras críticas exercidas por ambientalistas nacionais e entidades internacionais, direcionadas ao Banco Mundial (BIRD), principal agente financiador do POLONOROESTE, determinou uma mudança nas diretrizes dos programas oficiais. Anteriormente, a condição exigida pelos órgãos oficiais para obtenção do Título Definitivo da terra era a comprovação de benfeitoria no espaço, realizado sob a forma de desmatamento de determinada quantidade de hectares e plantio de pastagem, com a posse de pelo menos meia dúzia de cabeças de gado, processo que ficou conhecido como "agropecuária de fachada". Mais tarde, o BIRD passou a exigir do Estado, como garantia de financiamento, a criação de diversas Unidades de Conservação (UC), alinhando assim os planos de desenvolvimento aos protocolos mundiais de preservação ambiental. Estes fatos e o advento da ECO-92 convergiram para medidas corretivas, com uma segunda alternativa denominada Plano Agropecuário e Florestal de Rondônia (PLANAFLORO). Diante da demanda ambiental, o estabelecimento de UCs se fez necessário para garantir a integridade de parte do ecossistema florestal, numa débil tentativa de frear o desmatamento que adentrava a década de 1990 em plena atividade. No entanto, em muitos casos as UCs foram criadas sem levar em consideração as dinâmicas sociais e econômicas dos espaços entorno, nem as infraestruturas necessárias para gerenciamento das mesmas (Arnt \& Schwartzman, 1992; Becker, 1982; Fearnside, 1985; Ferreira e Almeida, 2005; MMA, 1995; MMA, 2003; MMA, 2004; Ott, 2002; Pedlowski et al, 1999; Smeraldi e Millikan, 1995).

Ao longo de duas décadas, importantes Unidades de Conservação do Estado de Rondônia foram invadidas, exploradas indevidamente, subtraídas legalmente e, por fim, seis UCs foram revogadas, no ano de 2010. Gestão após gestão, governo após governo, repetiram-se as mesmas práticas de descaso para com tais espaços. As motivações para estas situações residem nos interesses políticos e econômicos que estas áreas representam, como os últimos espaços florestados intactos, "propícios" à expansão econômica na forma de exploração mineral e de madeira nobre, onde a floresta posteriormente dá lugar à "pata do boi" (Alencar et al., 2004; Cordovil, 2010; Fearnside, 1995; Mendonça, 2002; Rondônia, 1993; Santos, 2007; Veríssimo, A. e Ribeiro, 2007).

O principal objetivo deste trabalho foi conhecer o perfil dos ocupantes (grileiros e posseiros ${ }^{3}$ ) das terras da Floresta Estadual de Rendimento Sustentado do Rio Mequéns (FERS) do Rio Mequéns, bem como as características das propriedades instaladas dentro

\footnotetext{
Expressão usada para indicar a substituição sistemática de florestas por pastagens, destinadas à atividade agropecuária.

3 Pessoas que realizam processos de ocupação ilegal de terras pertencentes ao Governo Federal.
}

da UC. O estudo analisou os primeiros anos da existência da FERS do Rio Mequéns, período compreendido entre os anos de 1990 e 1994, visando identificar as estratégias utilizadas pelos ocupantes irregulares nas UCs para apropriação dos espaços destinados a proteção ambiental, em Rondônia.

\section{Área de Estudo}

Este estudo abordou o caso da Unidade de Conservação denominada Floresta Estadual de Rendimento Sustentado do Rio Mequéns, localizada no Estado de Rondônia, Brasil, e incluída no Sistema Nacional de Unidades de Conservação, constituindo-se área de proteção ambiental integrante do bioma Amazônia. Criada através do Decreto $n^{\circ} 4.573$ de 23 de março de 1990, com área de aproximadamente 425.844 ha e perímetro de $398.980 \mathrm{~km}$, à época integrava a estrutura básica do Instituto Estadual de Florestas de Rondônia (IEF/RO), autarquia estadual vinculada à Secretaria de Estado do Meio Ambiente (SEMARO), atualmente denominada Secretaria de Desenvolvimento Ambiental do Estado de Rondônia (SEDAM). A área da FERS do Rio Mequéns estava localizada em terras pertencentes aos municípios de Cerejeiras, Colorado do Oeste e Alta Floresta d'Oeste. A partir do desmembramento de tais municípios, ocorrido entre os anos de 1992 e 1995, a referida UC passou a integrar as terras dos municípios de Alto Alegre dos Parecis, Alta Floresta, Cerejeiras, Corumbiara e Pimenteiras, conforme Figura 1 (ITERON, 1994; MMA, 2000; Silva, 2014).

A referida UC localizava-se no sudoeste do Estado de Rondônia, sendo balizada pelas seguintes Coordenada Geográficas:

Quadro I

Coordenadas de localização da FERS do Rio Mequéns.

\begin{tabular}{|l|c|c|}
\hline \multicolumn{1}{|c|}{ Limites da UC } & Latitude & Longitude \\
\hline Extremo Norte & $12^{\circ} 28^{\prime} 58^{\prime \prime} \mathrm{S}$ & $61^{\circ} 56^{\prime} 24^{\prime \prime} \mathrm{W}$ \\
\hline Extremo Sul & $13^{\circ} 05^{\prime} 14^{\prime \prime} \mathrm{S}$ & $61^{\circ} 12^{\prime} 59^{\prime \prime} \mathrm{W}$ \\
\hline Extremo Leste & $12^{\circ} 47^{\prime} 54^{\prime \prime} \mathrm{S}$ & $61^{\circ} 06^{\prime} 07^{\prime \prime} \mathrm{W}$ \\
\hline Extremo Oeste & $12^{\circ} 49^{\prime} 52^{\prime \prime} \mathrm{S}$ & $61^{\circ} 18^{\prime} 13^{\prime \prime} \mathrm{W}$ \\
\hline
\end{tabular}

Fonte: Silva, 2014.

A UC em questão limitava-se a Norte com a Terra Indígena do Rio Mequéns, a Gleba ${ }^{4}$ Corumbiara e Terras da União. A Leste limitava-se com a Gleba Corumbiara e a Gleba Guaporé. A Sul fazia limite com a área proposta para compor o Parque Estadual de Corumbiara. E a Oeste limitava-se com a Reserva Biológica do Guaporé, compondo assim um mosaico de áreas protegidas de diferentes categorias. A referida reserva estava assentada em partes das Glebas Corumbiara, Rio Verde, Guaporé, Massaco e Imóvel Barranco Alto, terras de propriedade da União

${ }^{4}$ O termo gleba refere-se a parte de terrenos da União, ocupados por agricultores, mas que ainda não foram judicialmente divididos e atribuídos. No caso em questão, o termo corresponde já a um nome próprio que designa algumas áreas que anteriormente funcionaram como glebas. 


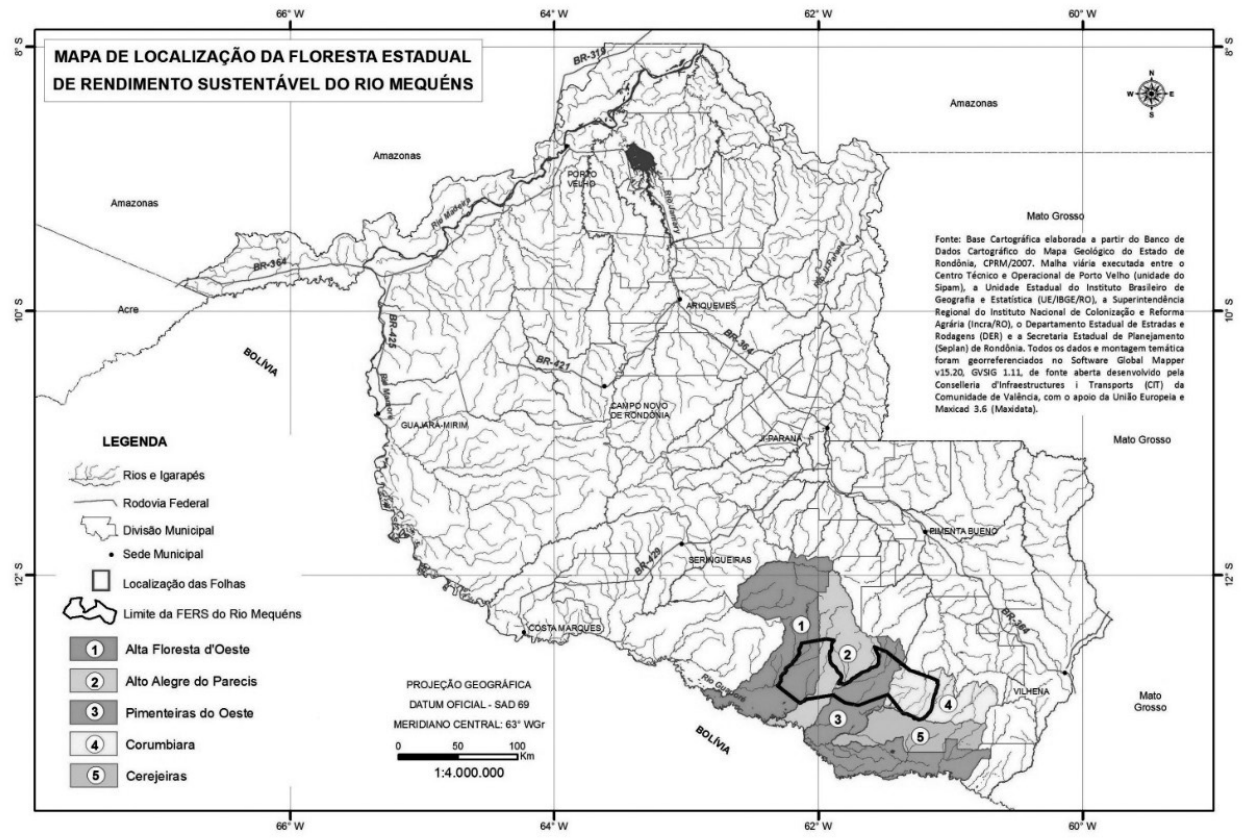

Figura 1

Mapa de localização da FERS do Rio Mequéns.

Fonte: Silva, 2014.

Federal, do INCRA e de particulares, conforme demonstra a Figura 2 (ITERON,1994; Silva, 2014).

Quanto à vegetação, a área abrangida pela UC apresenta cinco tipos de formação florestal, sendo elas áreas de florestas ombrófila e estacional, zonas de transição, savana/cerrado e formações pioneiras, subdivididas de acordo com suas especificidades, conforme apresentado no quadro 2.

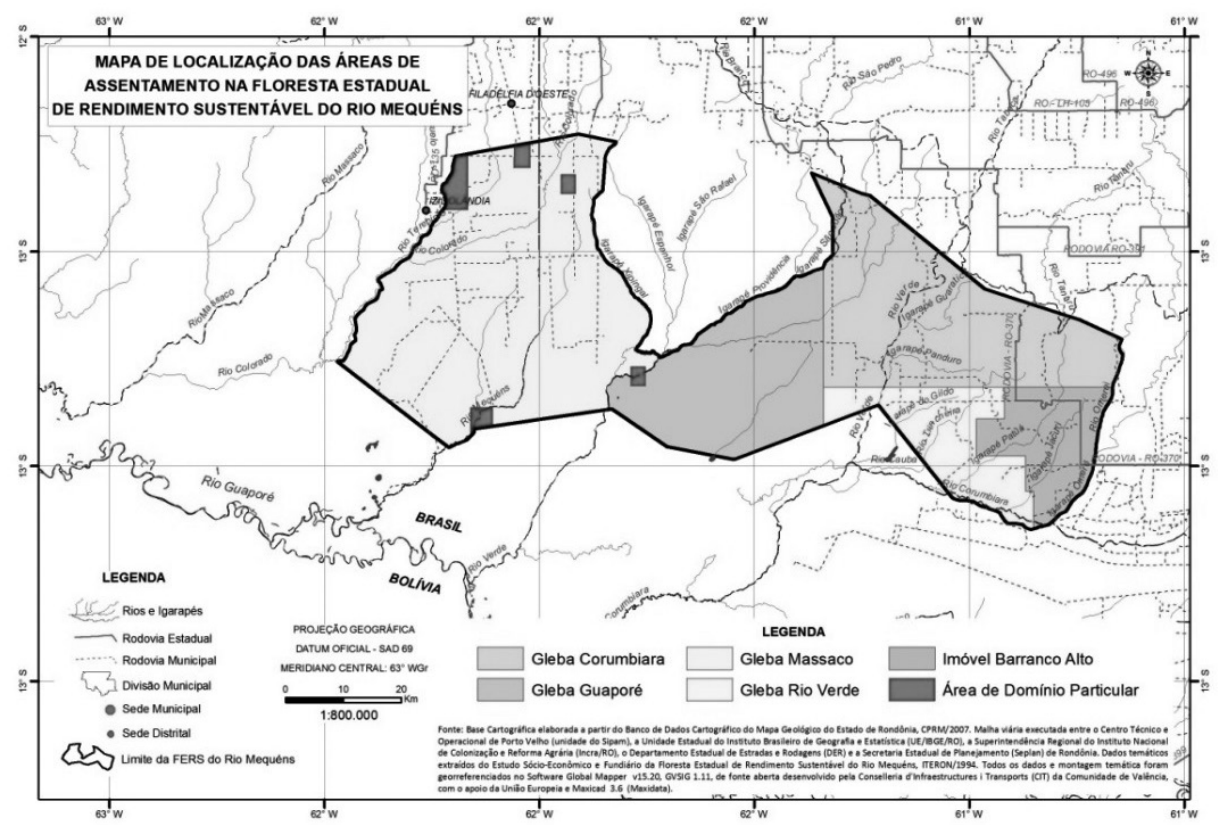

Figura 2

Mapa de localização das glebas que compunham a FERS do Rio Mequéns. Fonte: Silva, 2014. 
Quadro II

Caracterização da cobertura vegetal da FERS do Rio Mequéns.

\begin{tabular}{|c|c|}
\hline Formação florestal & Subdivisão \\
\hline \multirow{3}{*}{ Floresta ombrófila aberta } & Floresta ombrófila aberta submontana \\
\cline { 2 - 2 } & Floresta ombrófila aberta de terras baixas \\
\cline { 2 - 2 } Floresta estacional & Floresta ombrófila aberta alluvial / floresta de áreas inundáveis \\
\cline { 2 - 2 } & Floresta estacional semidecidual aluvial \\
\hline \multirow{3}{*}{ Savana } & Savana arborizada (cerrado arbóreo arbustivo) \\
\cline { 2 - 2 } & Savana florestada (cerradão) \\
\cline { 2 - 2 } & Savana gramíneo lenhosa (cerrado herbáceo arbustivo: campo \\
& limpo, sujo e murundu) \\
\hline \multirow{3}{*}{ Formação pioneira } & Formação pioneira sob influência fluvial arbustiva \\
\cline { 2 - 2 } & Formação pioneira sob influência fluvial arbustiva e/ou herbácea \\
\cline { 2 - 2 } & Formação pioneira sob influência fluvial arbórea \\
\cline { 2 - 2 } & Formação pioneira sob influência fluvial herbácea e/ou gramínea \\
\cline { 2 - 2 } & Formação pioneira sob influência fluvial de buritis (buritizal) \\
\hline \multirow{2}{*}{ Área de tensão ecológica } & Contacto floresta ombrófila/floresta estacional semidecidual \\
\cline { 2 - 2 } & Contacto savana/floresta ombrófila \\
\hline
\end{tabular}

Fonte: Silva, 2014.

Na Figura 3 observa-se a distribuição destas formações, dentro do espaço abangido pela FERS do Rio Mequéns. No mapa ressalta a importância da formação de Floresta Ombrófila Aberta, a mais extensa formação florestal da área, com as suas diferentes subdivisões. Destaca-se também o facto de grande parte desta formação estar a ser progressivamente substituída, com significativa área desmatada para consolidação de atividades agrícolas e agropecuárias, apresentada no mapa como “área antropizada”, nomeadamente no sector oriental.

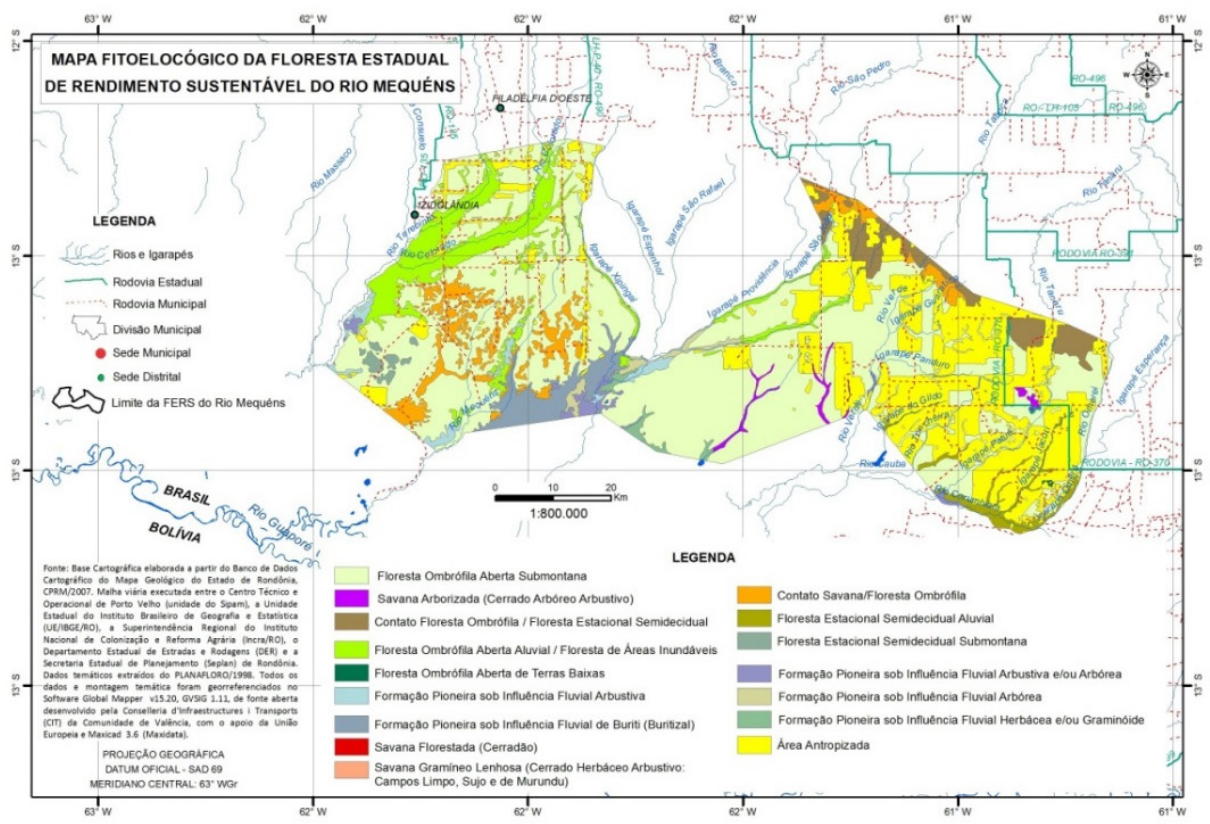

Figura 3

Mapa fitoecológico da FERS do Rio Mequéns.

Fonte: Silva, 2014. 
do Rio Mequéns habitavam, no ano de 1994, 210 famílias que somavam 1092 habitantes (ITERON, 1994; Silva, 2014).

\section{Materiais e Métodos}

0 artigo foi elaborado através de pesquisa bibliográfica e baseou-se em documentos da época (década de 1990) produzidos pelo PLANAFLORO, pela SEDAM, pelo Instituto de Terras e Colonização de Rondônia (ITERON) e informações do acervo técnico do Zoneamento Sócio Econômico e Ecológico do Estado de Rondônia (ZSEE/RO). Com base nestas referências, levantaram-se os programas oficiais implementados no Estado, a tipologia de ocupação ocorrida, a criação de Unidades de Conservação estaduais, o processo de ocupação de áreas protegidas e o processo de revogação de Unidade de Conservação, realizado no ano de 2010. Levantaram-se ainda os dados de ocupação referentes à FERS do Rio Mequéns, com informações sobre a área ocupada, o tipo de ocupação, o tamanho das propriedades estabelecidas, o uso do solo e as características da população residente na referida UC, entre os anos de 1990 e 1994.

O mapeamento apresentado foi construído através dos softwares Gobal Mapper v15.20, GVSIG 1.11, MaxiData/MaxiCAD 3.6 e do SIG ArcGis 10, com base em banco de dados diversos como da Companhia de Pesquisa de Recusos Minerais (CPRM/2007), Sistema de Proteção da Amazônia (SIPAM), Instituto Brasileiro de Geografia e Estatística (IBGE), INCRA, Departamento Estadual de Estradas e Rodagem (DER/RO), Secretaria Estadual de Planejamento (SEPLAM/RO).

$O$ presente trabalho fez parte das pesquisas para a construção da Dissertação de Mestrado sobre a "Revogação de Unidades de Conservação no Estado de Rondônia - O Caso da Floresta Estadual de Rendimento Sustentado do Rio Mequéns" (SILVA, 2014), apresentada ao Programa de Pós Graduação Desenvolvimento Regional e Meio Ambiente da Fundação Universidade Federal de Rondônia.

\section{Resultados}

O processo de ocupação ilegal e desordenado de uma área devoluta e/ou protegida, acontece baseado em fatores diversos. Entre estes, o acesso proporcionado por uma malha viária estruturada, as mudanças geopolíticas e territoriais na região, as características físicas propícias a certas atividades econômicas como a agricultura, a pecuária e a atividade madeireira (disponibilidade de terras, clima favorável e solos férteis), os interesses agrários (estrutura fundiária baseada nas grandes propriedades e processo de concentração de terra), os interesses sociais (estabelecimento em propriedades e cultivo da terra), principalmente econômicos (posse de grandes propriedades e exploração econômica da mesma) e políticos (estabelecimento de redutos eleitorais) são decisivos para garantir a força motriz que impulsiona as situações de grilagem e posseamento dentro das UCs. A pressão antrópica sobre áreas protegidas está pautada principalmente nestes fatores. Assim, vejamos como esta pressão antrópica tem acontecido ao longo de 20 anos de existência, na UC objeto desta investigação, a Floresta Estadual de Rendimento Sustentável do Rio Mequéns.

Sobre a FERS do Rio Mequéns, o ITERON elaborou, no ano de 1994, um Estudo Sócio-Econômico e Fundiário da mesma, no qual produziu uma série de dados importantes sobre a situação fundiária da UC em questão, uma vez que havia interesse do ITERON na regulamentação das propriedades existentes dentro dos limites desta área. No referido estudo verificou-se que a FERS do Rio Mequéns, à epoca de sua criação em 1990, já possuía algumas propriedades documentadas, conforme apresentado na Figura 4. Anteriormente, quando a área pertencia ao Estado do Mato Grosso, este expediu 7 documentos de regularização de terras, que correspondem apenas a $0,86 \%$, e após a criação do Território Federal de Rondônia, o INCRA expediu 111 Títulos de Terra, que correspondem a $51,72 \%$ da área que passou a compor a UC. Entretanto muitos dos imóveis constatados dentro da área de proteção correspondiam a propriedades ilegais, 442 em 477, ou seja 92,66\%, conforme se demonstra a Figura 5.

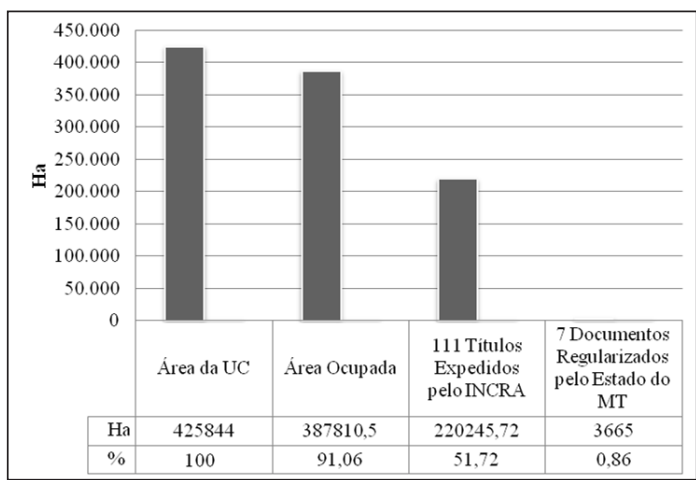

Figura 4

Situação documental dos imóveis na FERS do Rio Mequéns - 1994. Fonte: Silva, 2014.

Quanto ao uso da terra dentro da UC, em grande parte das áreas ocupadas explorou-se a madeira comercial e, após a extinção da cobertura original, as áreas passaram a ser utilizadas em sua maioria para pastagem, tendo um pequeno percentual sido usada para agricultura. Uma parte da área encontrava-se, mesmo, em situação de abandono com composição de pastagem-suja ${ }^{5}$ ou capoeira ${ }^{6}$, conforme a Figura 6.

\footnotetext{
5 Áreas de pastagem semiabandonadas, com predomínio de vegetação herbácea, presença de gramíneas, formas arbustivas e restabelecimento inicial da vegetação natural, apresentando vários estágios sucessionais. 6 Vegetação secundária composta por gramíneas e arbustos esparsos. 0 termo capoeira é oriundo da língua Tupi e designa o mato que nasceu no lugar de vegetação cortada. Significa, literalmente, "mato do passado", de ka'a ("mato") e uera (“do passado").
} 


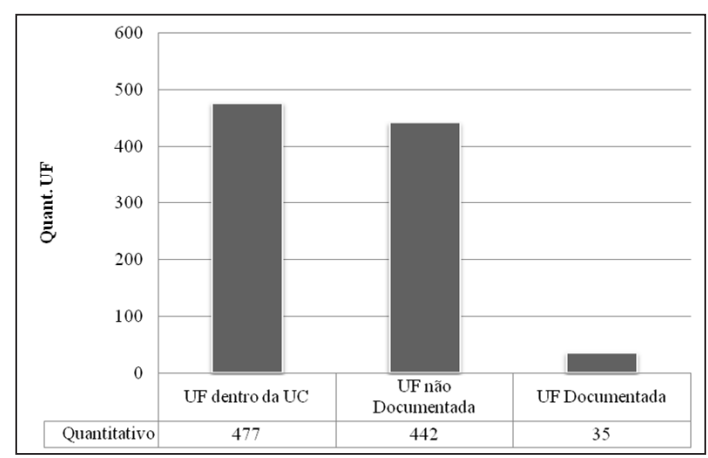

Figura 5

Situação dominial da FERS do Rio Mequéns - 1994

Fonte: Silva, 2014

Outra situação relevante diz respeito aos proprietários dos imóveis estabelecidos dentro da FERS do Rio Mequéns. Os dados produzidos pelo ITERON (1994) permitem perceber a presença de 25 grandes

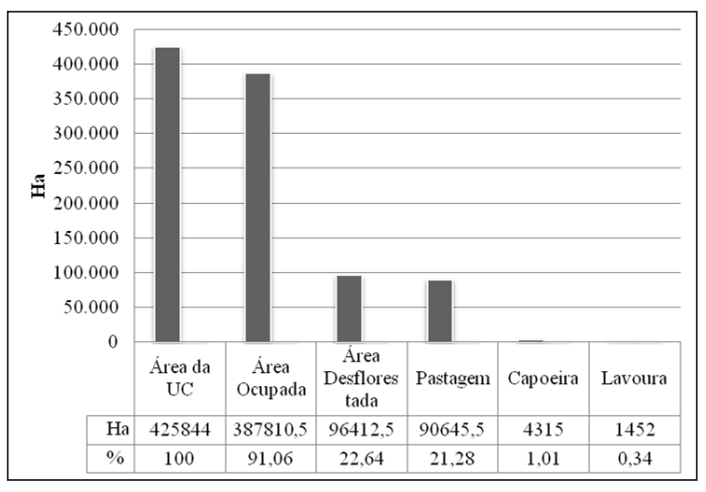

Figura 6

Uso da terra na FERS do Rio Mequéns - 1994

Fonte: Silva, 2014

proprietários e/ou grupos econômicos que detinham a posse ilegal de propriedades de grande extensão territorial, acima de $500 \mathrm{ha}$, conforme demonstra a Figura 7.

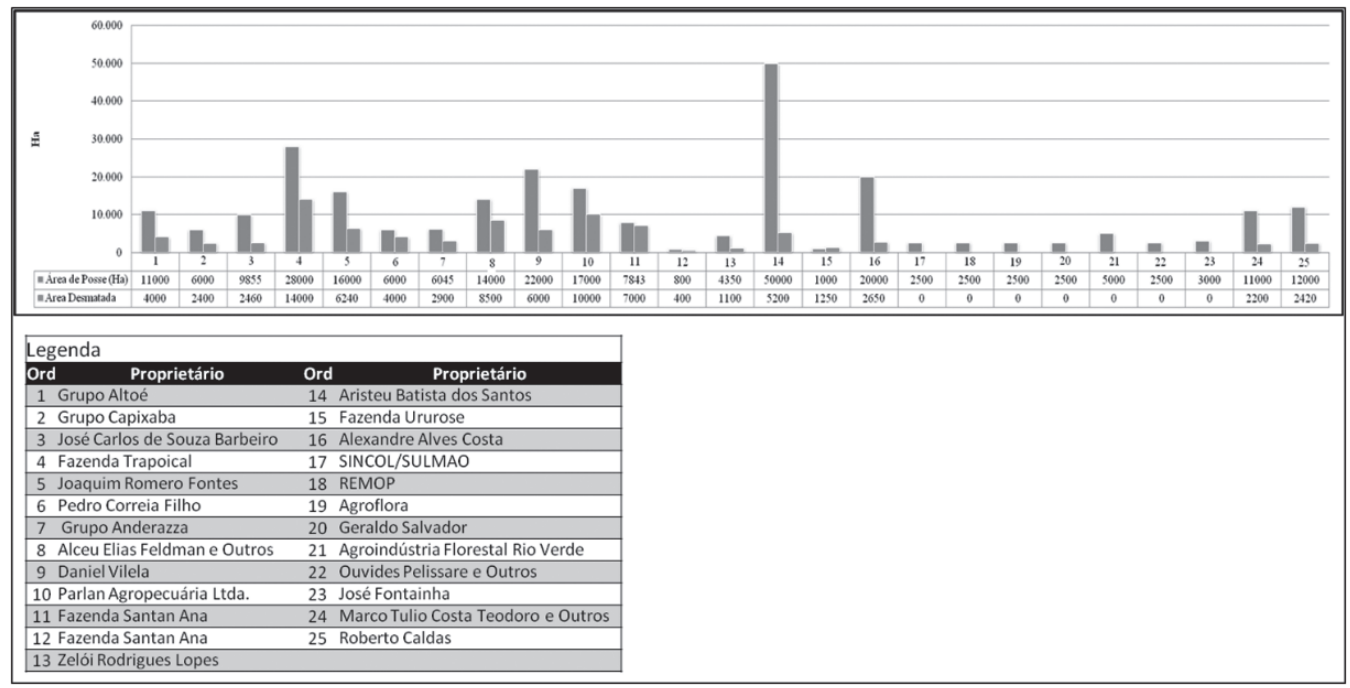

Figura 7

Grande proprietários e grupos econômicos na FERS do Rio Mequéns - 1994.

Fonte: Silva, 2014.

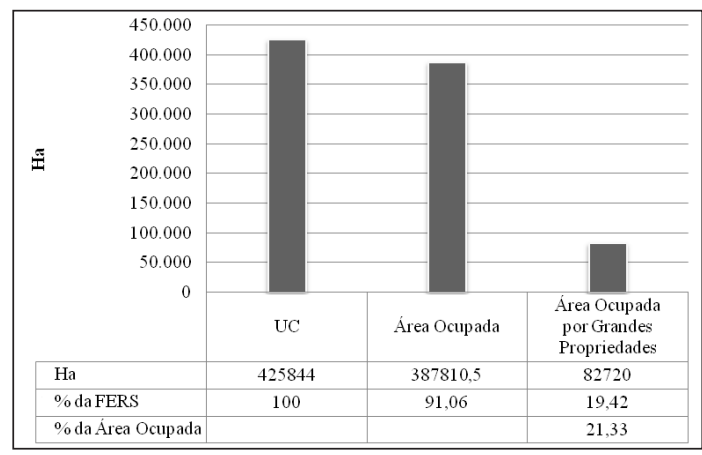

Figura 8

Grande proprietários e grupos econômicos na FERS do Rio Mequéns - 1994. Fonte: Silva, 2014.

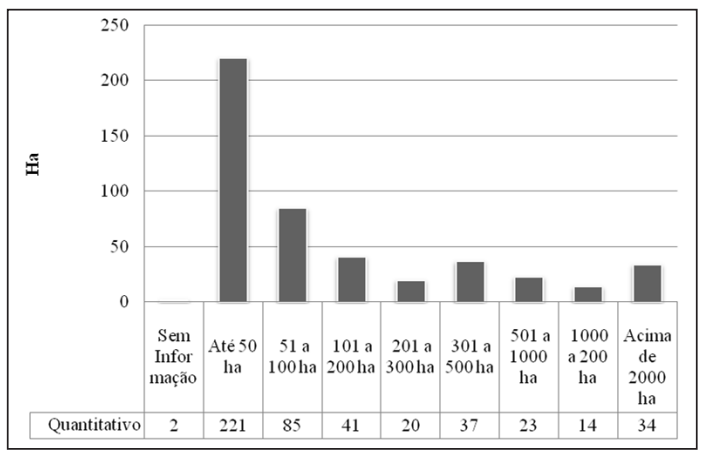

Figura 9

Dimensão dos imóveis na FERS do Rio Mequéns - 1994.

Fonte: Silva, 2014. 
A área detida por famílias poderosas e grandes grupos econômicos era significativa, correspondendo a $19,42 \%$ da área total da FERS do Rio Mequéns e a $21,33 \%$ da área ocupada dentro da UC, conforme sintetiza a Figura 8.

Um outro aspecto interessante diz respeito à dimensão das propriedades existentes dentro da UC em questão. A maioria das terras estavam concentradas nas mãos de médios e grandes proprietários, com propriedades respetivamente acima de 100 e 500ha. A concentração fundiária, tão comum no Brasil desde a chegada dos Portugueses e a implantação das Capitanias Hereditárias, ainda se reproduz nos rincões amazônicos, conforme se observa na Figura 9.

Em relação ao tempo de ocupação das propriedades, é possível verificar que a maioria foi ocupada nos últimos 5 anos anteriores ao estudo, ou seja entre 1990 e 1994, já após a criação da UC, conforme apresentado na Figura 10.

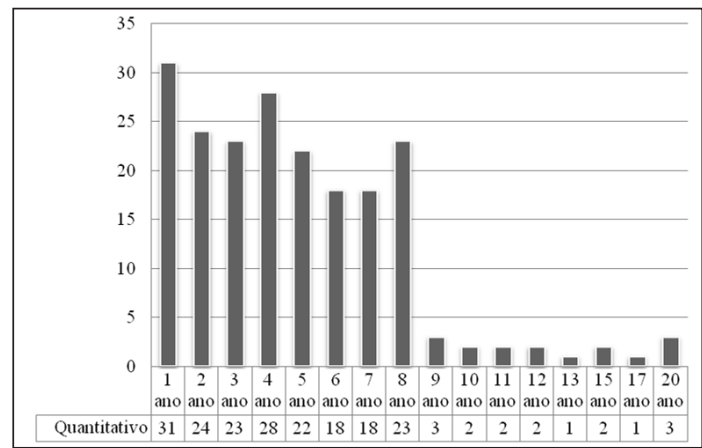

Figura 10

Tempo de ocupação dos imóveis na FERS do Rio Mequéns - 1994. Fonte: Silva, 2014

Entretanto, é importante ressaltar que, quanto à ocupação dos imóveis, identificou-se que mais da metade encontrava-se em situação de abandono, com famílias habitando em um quantitativo menor de propriedades, conforme verifica-se na Figura 11.

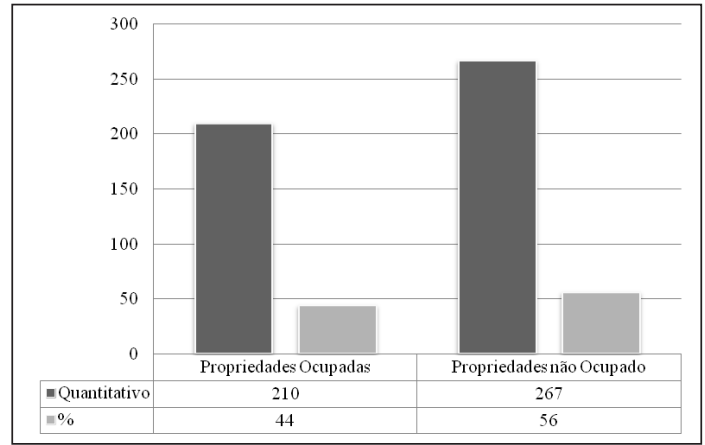

Figura 11

Ocupação dos imóveis na FERS do Rio Mequéns.

Fonte: Silva, 2014.

No tocante à população residente na FERS do Rio Mequéns, verificou-se que 210 famílias habitavam as 210 propriedades ocupadas existentes na UC, somando um total de 1092 residentes, conforme apresentado na Figura 12.

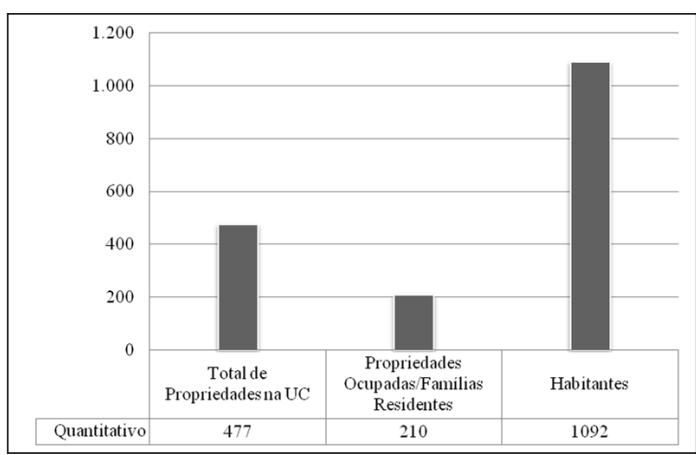

Figura 12

Ocupação dos imóveis na FERS do Rio Mequéns.

Fonte: Silva, 2014

\section{Conclusão}

As frágeis políticas ambientais e a forte expansão econômica que caracterizou a história do Estado de Rondônia foram fundamentais para os processos de desflorestamento e de avanço da ocupação sobre áreas de proteção ambiental. Se, por um lado, o poder público não dispunha de mecanismos e recursos para fazer cumprir as diretrizes e a legislação ambiental, por outro lado o mesmo poder público, através de órgãos e programas oficiais, fomentou a busca por novos espaços de produção com vista ao crescimento econômico. Aliados a esses incentivos, outros fatores contribuíram significativamente para o fortalecimento de frentes de ocupação, tal como a abertura de novos eixos rodoviários internos, conectando as linhas vicinais que davam acesso aos núcleos e aglomerações urbanas dos projetos de assentamento; a divisão territorial que aconteceu no Estado na década de 1990, com a criação de novos municípios; a necessidade destes novos municípios de estabelecerem sua sustentabilidade e autossuficiência econômica; o aumento populacional do Estado, em especial o aumento da população economicamente ativa nos municípios que a UC estava inserida; a diversificação da economia; as novas tecnologias na agricultura que possibilitam o incremento da produtividade. Um outro fator significativo foi o surgimento de novos elementos protagonizados pelo Movimento dos Sem Terra (MST) e pela Via Campesina, entre outros movimentos de luta pela posse da terra agrícola para instalação da agricultura familiar, surgido pelo fenômeno da agregação de terra que ocorre na Amazônia como um todo e, particularmente, em Rondônia.

Este trabalho buscou identificar e compreender todos os elementos que de alguma forma contribuíram para a consolidação dos processos de grilagem e posseamento em Unidades de Conservação. Para os objetivos oficiais do PLANAFLORO, esta e outras UCs deveriam garantir a preservação de uma percen- 
tagem considerável da cobertura vegetal natural do Estado de Rondônia, porém, na prática, a criação de áreas de preservação tinha por meta cumprir exigências do BIRD, financiador do Plano, segundo o qual os recursos financeiros para o PLANAFLORO somente seriam liberados mediante a garantia da criação de Unidades de Conservação no Estado, alinhando assim o Plano às diretrizes ambientais adotadas por esta Instituição. Não houve estudos prévios das características físicas e ambientais, ocupação anterior e aptidão econômica nas áreas criadas.

A coordenação do PLANAFLORO precisava criar estas áreas e ao mesmo tempo enfrentava a concorrência por terras públicas com as frentes de ocupação do Estado. Não houve o empenho e o interesse dos órgãos ambientais em cumprir as etapas necessárias à efetiva sustentabilidade de longo prazo das áreas de proteção, tornando-as, ao longo dos anos, unidades fantasma, que existiam apenas de Direito. Esta situação de abandono abriu margem para os processos de ocupação ilegal desta área. O Estado tinha consciência destes processos de ocupação ilegal, conforme demonstrado pelos estudos do ITERON (1994), no entanto o poder público não desenvolveu ações que garantissem a reintegração das áreas ocupadas e que coibissem os processos de grilagem e posseamento.

0 presente estudo permitiu compreender os interesses econômicos e políticos relacionados com a área estudada e a sua revogação, bem como os mecanismos de ocupação dos grandes e pequenos empreendimentos. 0 grande número de famílias que praticam a agricultura na FERS do Rio Mequéns é representativo e preocupante, pois se, por um lado se considera a degradação das áreas ocupadas, por outro lado há o fator social que é inegável, uma vez que as áreas de proteção são a fonte de renda e de sustento de considerável parcela daquela população, tornando a situação mais delicada, também pelo fator político que estas famílias representam. Esta população constitui-se de cidadãos votantes, portanto atrai interesses políticos e estabelece-se uma situação de "escambo" onde, se atendendo os interesses da referida população pela posse da terra, propicia-se aos políticos regionais garantias de "currais eleitorais" ad aeternum.

Entretanto, outro fator significante dentro do processo de ocupação de áreas protegidas no Estado de Rondônia é a forte presença de grandes grupos econômicos. Os mesmos detêm a posse de grandes áreas destinadas à exploração mineral e madeireira, à agropecuária extensiva e, mais recentemente, à monocultura da soja. A maioria destes grupos econômicos não são sediados no Estado, tendo suas matrizes localizadas no sudeste brasileiro.

Este fato, em especial, converge indubitavelmente para a submissão das autoridades locais, uma vez que o poder econômico destes grupos e a sua capacidade de geração de divisas os coloca em relação direta com os representantes políticos dentro e fora do Estado, cujas decisões são manipuladas em Brasília, no Senado e na Câmara Federal, quando se trata do desmonte das Unidades de Conservação e
Terras Indígenas. O cerne da questão, entretanto, reside na omissão do Estado, enquanto gestor e responsável pelas UCs estaduais, incluindo a FERS do Rio Mequéns, que durante os vinte anos de existência legal, ficou exposta a intenso e constante processo de ocupação ilegal, que não foi combatido. A negligência do poder público em garantir a integridade desta UC permitiu a subtração da área de preservação, formalizou a revogação da Unidade de Conservação e garantiu a perpetuação dos processos de grilagem e posseamento no Estado de Rondônia, através do precedente que abriu.

\section{Bibliografia}

Alencar, A; Nepstad, N.; Mcgrath, D.; Moutinho, P.; Pacheco, P.; Diaz, M. D. C. V. \& Filho, B. S. (2004). Desmatamento na Amazônia: indo além da emergência crônica. Manaus: Instituto de Pesquisa Ambiental da Amazônia (INPA), 89 p.

Arnt, R. A. \& Schwartzman, S. (1992). Um artifício orgânico. Transição na Amazônia e ambientalismo (1985-1990). Rio de Janeiro: Rocco, $366 \mathrm{p}$.

Azevedo, A. M. \& Delgado, C. C. (2002). Mineração, meio ambiente e mobilidade populacional: um levantamento nos estados do centro-oeste expandido. XIII Encontro da Associação Brasileira de Estudos Populacionais. Unicamp, 23 p. Disponível em: http://www.abep. nepo.unicamp.br/docs/anais/pdf/2002/GT_MA_PO30_ Azevedo_texto.pdf. Acesso em: 10 de outubro de 2012.

Becker, B. K. (1982). Geopolítica da Amazônia: a nova fronteira de recursos. Rio de Janeiro: Zahar, $233 \mathrm{p}$.

Becker, B. K. (2007). Amazônia: geopolítica na virada do III milênio. Rio de Janeiro: Garamound, 172 p.

Cordovil, V. R. S. (2010). A situação das unidades de conservação em Rondônia: $O$ caso Cujubim. Dissertação do Programa de Mestrado de Geografia. Porto Velho: UNIR, $174 \mathrm{p}$.

Dantas, J. A. (2010). A nossa Geografia - Rondônia. Porto Velho: Sawa Editora, 103 p.

Fearnside, P. (1985). Rondônia: a farsa das reservas. Ciências Hoje (SBPC), 3(17), 90-92.

Fearnside, P. (1991). Rondônia: estradas que levam à devastação. Revista Ciência Hoje (SBPC), vol. Especial: Amazônia, 116-122.

Fearnside, P. (1995). Quem desmata a Amazônia, os pobres ou os ricos? Revista Ciência Hoje (SBPC). 19 (113), 26-33.

Fearnside, P. (2003). A floresta Amazônia nas mudanças globais. Manaus: Instituto Nacional de Pesquisas da Amazônia (INPA), 134 p. 
Fearnside, P. (2005). Desmatamento na Amazônia brasileira: história, índices e consequências. Megadiversidade, vol. $1, \mathrm{n}^{\circ} 1,113-123$.

Fearnside, P. (2006). Desmatamento na Amazônia: dinâmica, impactos e controle. Acta Amazonica. 3(36), 395-400.

Ferreira, L. V. Ventincinque, E. Almeida, S. (2005). O desmatamento na Amazônia e a importância das áreas protegidas. Estudos Avançados, 19 (53), 157-166.

FUNATURA - FUNDAÇÃO Pró-Natureza (1989). Sistema nacional de unidades de conservação (SNUC): aspectos conceituais e legais. Brasília: IBAMA/FUNATURA, 82 p.

Governo do Estado de Rondônia. 2013. Portal Eletrônico. Disponível em: http://www.rondonia.ro.gov.br/ conteudo.asp?id=180. Acesso em: 04 de agosto de 2013.

IBAMA - Instituto do Meio Ambiente e dos Recursos Naturais Renováveis. (2011). Dez anos do sistema nacional de unidades de conservação da natureza: lições do passado, realizações presentes e perspectivas para o futuro. Brasília: MMA.

IBGE - Instituto Brasileiro de Geografia e Estatística. (2013). Estados/Rondônia. Portal Eletrônico. Disponível em: http://www.ibge.gov.br/estadosat/perfil.php?sigla=ro. Acesso em: 04 de agosto de 2013.

INPE. (1992). Deforestation in Brazilian Amazonia. São Paulo, 2a edição, INPE.

INPE. (2004). Monitoramento da floresta amazônica brasileira por satélite: Projeto PRODES. São José dos Campos.

ITERON - Instituto de Terras e Colonização de Rondônia (1994). Estudo sócio-econômico e Fundiário da floresta estadual de rendimento sustentável do Rio Mequéns. NUPLAN Ltda. (Org.). Governo do Estado de Rondônia. Porto Velho.

ITERON - Instituto de Terras e Colonização de Rondônia (1996). Rondônia: Desenvolver e Preservar. S. A. Tenani (org.). ITERON/PNUD/INCRA/SEPLANAFLORO. Porto Velho, $20 \mathrm{p}$.

Laurance, W. L.; Albernaz. A. K. M.; Fearnside, P. M.; Vasconcelos, H. \& Ferreira, L. V. (2004). Deforestation in Amazonia. Science, 304, 1109-1111.

Leonel, M. (1992). Colonos contra amazônidas no polonoroeste: uma advertência às políticas. In Philippe Léna \& Adélia E. Oliveira (Org.), Amazônia: a fronteira agrícola 20 anos depois (pp. 319-329). Belém: CEJUP.

Matricardi, E. A. T. (1996). Uso e ocupação das terras rurais em Rondônia. PNUD/PLANAFLORO. Porto Velho, 122 p.

Mendonça, S. R. (2012). Estado e economia no Brasil: opções de desenvolvimento, $2^{\text {a }}$ ed. Rio de Janeiro: Graal, $112 \mathrm{p}$.
Miranda, E. E. de (1992). Avaliação do impacto ambiental da colonização em florestas amazônicas. In Philippe Léna \& Adélia E. Oliveira (Org.), Amazônia: a fronteira agrícola 20 anos depois (pp. 223-238). Belém: CEJUP.

MMA (1995). Política nacional integrada para a Amazônia legal. Brasília, 48 p.

MMA (2000). Sistema nacional de unidades de conservação - SNUC. Brasília. Disponível em: Http://www.mma. gov.br/areas-protegidas/sistema-nacional-de-ucs-snuc. Acesso em: 17/07/2012.

MMA (2003). Áreas prioritárias para a conservação, utilização sustentável e repartição de benefícios da biodiversidade brasileira. Brasília.

MMA (2004). Plano de ação para a prevenção e controle do desmatamento na Amazônia legal. Brasília.

Moran, E. F. (1993). Deforestation and land use in the Brazilian Amazon. Human Ecology, 21, pp. 1-21. Disponível em: https://www.msu.edu/ moranef/ documents/93-03_Deforestation_LandUse.pdf. Acessado em: 08 de agosto de 2012

Nunes, D. D. (1997). Desmatamento e Unidade de Conservação em Rondônia. Revista de Educação Cultura e Meio Ambiente. $\mathrm{n}^{\circ} 10$ (dez), vol. I, 1-12.

Oliveira, O. A. (2001). Geografia de Rondônia: espaço e produção. Porto Velho: Dinâmica, 204 p.

Oliveira, O. A. (2003). História: desenvolvimento e colonização de Estado de Rondônia. Porto Velho: Dinâmica, 111 p.

Ott, A. M. T. (2002). Dos projetos de desenvolvimento. Ao desenvolvimento dos projetos: o planafloro em Rondônia. Tese de doutorado interdisciplinar em Ciências Humanas. Universidade Federal de Santa Catarina. Florianópolis, $285 \mathrm{p}$.

Perdigão, F. \& Basségio, L. (1992). Migrantes amazônicos. Rondônia: a trajetória da ilusão. São Paulo: Edições Loyola. 224 p.

Pedlowski, M.; Dale, V. \& Matricardi, E. (1999). A criação de áreas protegidas e os limites da conservação ambiental em Rondônia. Ambiente \& Sociedade, 5, 93-107.

Rondônia - Secretaria de Desenvolvimento Ambiental (1996). Desmatamento em Rondônia (1978 a 1993). Porto Velho: SEDAM, $46 \mathrm{p}$.

Rondônia - Instituto de Terras e Colonização de Rondônia (1996). Rondônia: desenvolver e preservar. Porto Velho, ITERON, $20 \mathrm{p}$.

Santos, C. (1998). A territorialidade na colonização rondoniana. Tese de doutorado em Geografia. Universidade Federal do Rio de Janeiro. Rio de Janeiro, $153 \mathrm{p}$.

Santos, C. (2001). A fronteira do Guaporé. EDUfRO. Porto Velho, $216 \mathrm{p}$. 
Santos, C. (2007). Amazônia: uma ocupação paradoxal? Um ponto de vista a partir de Rondônia In Brasil, W. (Org.), Desenvolvimento regional e meio ambiente em Rondônia (pp. 165-190). Porto Velho: EDUfRO.

SEDAM - Secretaria de Estado de Desenvolvimento Ambiental (2010). Vinte e um anos de zoneamento socioeconômico e ecológico do estado de Rondônia. Porto Velho, $59 \mathrm{p}$.

Silva, J. T. (2014). Revogação de unidades de conservação no estado de Rondônia: o caso da floresta estadual de rendimento sustentado do Rio Mequéns. Dissertação de mestrado. PGDRA/UNIR. Porto Velho, $95 \mathrm{p}$.

Smeraldi, R. \& Millikan, B. (1995). Pedido de investigação apresentado ao Painel de Inspeção do Bando Mundial sobre o PLANAFLORO. Forum das ONG'S de RO/Friends of The Earth. Porto Velho, $57 \mathrm{p}$.

SNUC. (2002). Sistema nacional de unidades de conservação: texto da Lei 9.985 de 18 de julho de 2000 e vetos da Presidência da República ao PL aprovado pelo
Congresso Nacional. $2^{\text {a }}$ ed. ampliada. São Paulo: Conselho Nacional da Reserva Biosfera Mata Atlântica, $76 \mathrm{p}$.

Tocantins, L. (1982). Amazônia: Natureza, Homem e Tempo: uma planificação ecológica. $2^{\mathrm{a}}$ ed. Rio de Janeiro: Civilização Brasileira, 177 p.

Vallejo, L. R. (2009). Unidade de conservação: uma discussão teórica á luz dos conceitos de território e políticas públicas. GEOgraphia, América do Norte, 4, set. Disponível em: http://www.uff.br/geographia/ojs/ index.php/geographia/article/view/88/86. Acesso em: 26 Ago. 2013.

Veríssimo, A. \& Ribeiro, B. (2007). Padrões e causas do desmatamento nas áreas protegidas de Rondônia. Revista Natureza e Conservação, 5, 15-26.

Texto recebido em/Text submitted on: 21/03/2016 Texto aprovado em/Text approved on: 01/07/2016 